\title{
INSTITUTIONALIZATION PATTERNS IN BREAST CANCER IMMUNOHISTOCHEMISTRY
}

\author{
Galina Yaneva $^{1}$, Tsonka Dimitrova ${ }^{1}$, Dobri Ivanov ${ }^{1}$, Gergana Ingilizova $^{2}$, Sergei \\ Slavov $^{3}$ \\ 1) Department of Biology, Faculty of Pharmacy, Medical University of Varna, \\ Bulgaria \\ 2) “Vita” Multidisciplinary Hospital for Active Treatment of Sofia, Bulgaria \\ 3) University Hospital of Obstetrics and Gynecology "Maichin Dom”, Sofia, \\ Bulgaria.
}

\begin{abstract}
Purpose: The objective of the present study is to analyze scientometrically some essential patterns of the dynamic science institutionalization on breast cancer immunohistochemistry and to outline the most significant scientists, journals, scientific institutions conference proceedings in this interdisciplinary field.

Material/Methods: In December 2019, a retrospective problem-oriented, title-word based search was performed in Web of Science Core Collection (WoS), MEDLINE and BIOSIS Citation Index (BIOSIS) of Web of Knowledge as well as in Scopus for 2003-2018. The following parameters were comparatively assessed: annual dynamics of publications, author's names, journal titles, scientific institutions, and scientific forums.

Results: There were 1187 publications abstracted in WoS, 776 publications abstracted in BIOSIS, 711 publications abstracted in Scopus, and 616 publications abstracted in MEDLINE. There were journal articles in 288 journals abstracted in WoS, in 234 journals abstracted in MEDLINE, in 156 journals abstracted in Scopus, and in 140 journals abstracted in BIOSIS. The most productive authors were David G. Hicks, Rohit Bhargava and Ian O. Ellis. The 'core' journals were Modern Pathology, Laboratory Investigation and Cancer Research. The most influential scientific institutions were the University of Texas System (USA) and the University of Texas MD Anderson Cancer Center (USA). The annual meetings of the US and Canadian Academy of Pathology and the Annual San Antonio Breast Cancer symposia were most attractive to the investigators worldwide.
\end{abstract}

Conclusion: Our comprehensive results could be of interest to breast cancer researchers and clinicians from smaller countries, institutional science managers, and journal editors.

Keywords: breast cancer immunohistochemistry, scientometrics, research institutionalization, data-bases

\section{INTRODUCTION}

Breast cancer is a major public health concern worldwide, and its global incidence landscape is critical for primary prevention and disease burden reduction [1]. In recent decades, there has been a permanent interest in the applications of modern immunohistochemical methods in breast cancer patients.

In 720 women with breast cancer, lower leptin receptor immunohistochemical expression within the breast tumor microenvironment might contribute mechanistically to inter-individual variation in aggressive breast cancer clinicopathology, particularly estrogen receptor-negative status and triple-negative subtype [2]. The results from two large, multicentre, non-interventional studies in Germany demonstrate that reliable, high-quality human epidermal growth factor receptor 2-testing methods are essential for the selection of patients with human epidermal growth factor receptor 2-positive breast cancer for human epidermal growth factor receptor 2-targeted treatment [3].

The objective of the present study is to analyze scientometrically some essential patterns of the dynamic science institutionalization on breast cancer immunohistochemistry and to outline the most significant scientific institutions, scientists, conference proceedings, and journals in this interdisciplinary field.

\section{MATERIALS \& METHODS}

In December 2019, a retrospective problem-oriented, title-word based search was performed in Web of Science Core Collection (WoS), MEDLINE and BIOSIS Citation Index (BIOSIS) of Web of Knowledge (Clarivate Analytics, Philadelphia, PA, USA) as well as in Scopus (Elsevier, Amsterdam, Netherlands) for 2003-2018. The following scientometric parameters of the publication output and citation activity were comparatively assessed: i) annual and total number of abstracted publications; ii) author's names and number of publications; iii) journal titles and number of publications; iv) country belonging and number of publications of scientific institutions, and v) titles of scientific forums and number of publications in their proceedings.

Some scientometric distributions only were demonstrated and briefly interpreted. 


\section{RESULTS}

There were 1187 publications abstracted in WoS, 776 publications abstracted in BIOSIS, 711 publications abstracted in Scopus, and 616 publications abstracted in MEDLINE. The annual dynamics of publications on the topic abstracted in these databases is illustrated in Figure 1. A relatively constant publication output was evident as its reduction in 2018 was due to time lag between primary publishing and subsequent abstracting.

Fig. 1. Annual dynamics of the number of publications on the topic abstracted in four databases

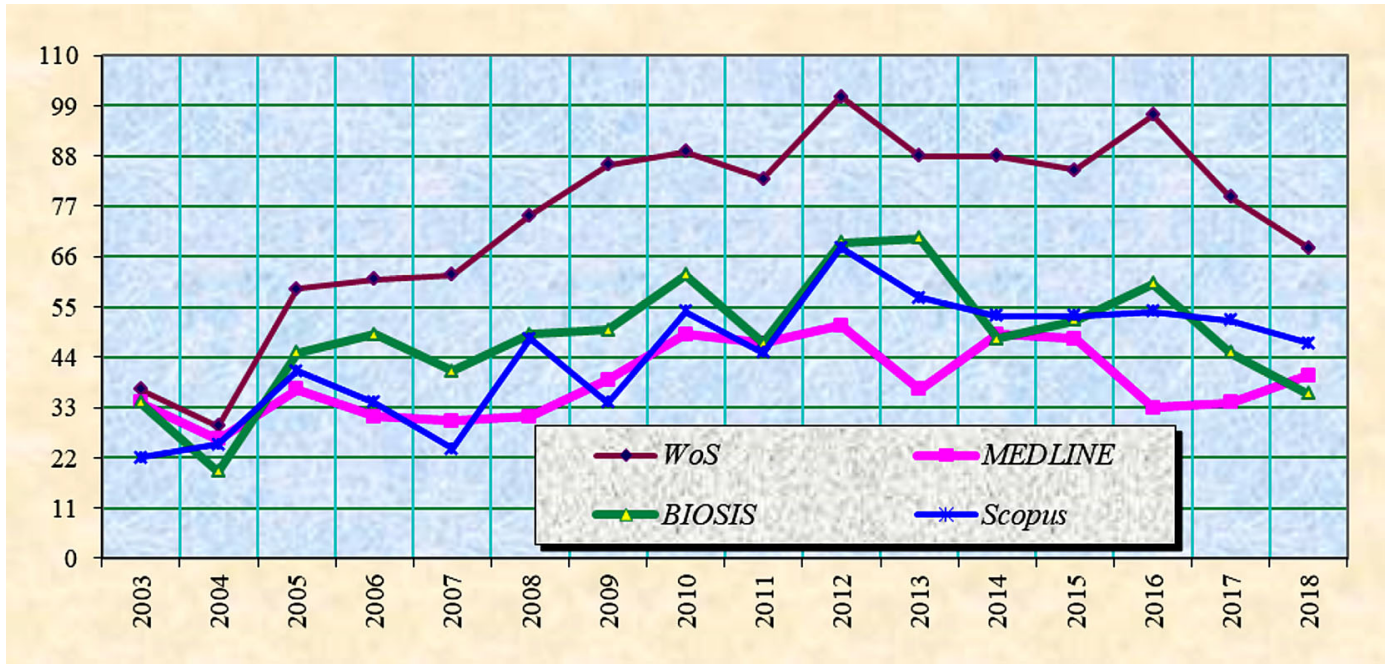

Original journal articles prevailed in Scopus and MEDLINE and occupied a second place after meeting abstracts in WoS and BIOSIS, presenting with 562 articles versus 568 meeting abstracts and with 348 articles versus 421 meeting abstracts, respectively. There were 19 versus 20 congress proceedings (1.60\% versus $2.81 \%)$ in $W o S$ and Scopus only, respectively.
There were journal articles in 288 journals abstracted in WoS, 234 journals abstracted in MEDLINE, 156 journals abstracted in Scopus, and 140 journals abstracted in BIOSIS.

The names, countries of occupation and numbers of publications of the 12 most productive authors are displayed in Table 1. The USA prevailed among these five countries of researchers on this topic.

Table 1. Most productive authors on the topic in four databases

\begin{tabular}{|c|l|l|l|c|c|c|}
\hline Rank & \multicolumn{1}{|c|}{ Authors } & Country & WoS & BIOSIS & Scopus & MEDLINE \\
\hline 1. & David G. Hicks & USA & 22 & 12 & 10 & 8 \\
\hline 2. & Rohit Bhargava & USA & 20 & 17 & 6 & 8 \\
\hline 3. & Ian O. Ellis & UK & 20 & 14 & 12 & 13 \\
\hline 4. & L. C. Goldstein & USA & 18 & 11 & - & 2 \\
\hline 5. & Allen M. Gown & USA & 17 & 13 & 3 & 4 \\
\hline 6. & David J. Dabbs & USA & 16 & 15 & 10 & 10 \\
\hline 7. & Andrew R. Green & UK & 14 & 10 & 6 & 4 \\
\hline 8. & Charles M. Perou & USA & 14 & 10 & 7 & 6 \\
\hline 9. & Torsten O. Nielsen & Canada & 12 & 4 & 7 & 7 \\
\hline 10. & P. H. Tan & Singapore & 11 & 10 & 7 & 7 \\
\hline 11. & Jacek Jassem & Poland & 10 & 6 & 7 & 5 \\
\hline 12. & Ja Seung Koo & Korea & 10 & & 5 \\
\hline
\end{tabular}

The number of the articles published in the so-called 'core' journals containing most papers on the topic was listed in Table 2. These 12 top journals differed in single databases, and these differences were particularly manifested concerning Scopus and MEDLINE. The American Journal of Clinical Pathology contained 22 and 13 articles ab- stracted in MEDLINE and Scopus, BMC Cancer - 11 and 19 articles, and Anticancer Research - 12 and 16 articles, respectively. In addition, in MEDLINE, there were 14 papers abstracted from Breast Cancer (Tokyo) and 12 papers from Histopathology and Human Pathology each, while in Scopus, there were 13 papers from Archives of Pathology 
and Laboratory Medicine and 10 papers from the British Journal of Cancer, respectively. In WOS, 12 'core' journals represented $4.17 \%$ of the journals and contained $50.08 \%$ of the publications, while in BIOSIS, they represented $8.57 \%$ of the journals and contained $63.02 \%$ of the publi- cations on the topic. In Scopus, 12 'core' journals represented $7.69 \%$ of the journals and contained $25.04 \%$ of the publications, while in MEDLINE, they represented $5.13 \%$ of the journals and contained $24.35 \%$ of the publications on the topic.

Table 2. 'Core' journals on the topic in four databases

\begin{tabular}{|c|l|c|c|c|c|}
\hline Rank & \multicolumn{1}{|c|}{ Journal title } & WoS & BIOSIS & Scopus & MEDLINE \\
\hline 1. & Mod Pathol & 100 & 90 & 11 & 17 \\
\hline 2. & Lab Invest & 93 & 69 & 2 & 0 \\
\hline 3. & Cancer Res & 87 & 82 & 0 & 0 \\
\hline 4. & Virch Arch & 65 & 66 & 2 & 7 \\
\hline 5. & J Clin Oncol & 61 & 0 & 14 & 7 \\
\hline 6. & Breast Cancer Res Treat & 55 & 55 & 19 & 15 \\
\hline 7. & Ann Oncol & 39 & 0 & 6 & 5 \\
\hline 8. & Eur J Cancer (+Suppl) & 39 & 38 & 5 & 6 \\
\hline 9. & Breast & 25 & 20 & 12 & 10 \\
\hline 10. & Appl Immunohistochem Mol Morphol & 19 & 22 & 23 & 17 \\
\hline 11. & BMC Cancer & 18 & 14 & 9 & 11 \\
\hline 12. & Histopathology & 0 & 9 & 12 \\
\hline
\end{tabular}

There were 16 specialized journals containing the terms 'breast' and 'histochemistry' in their titles (Table 3). They were attractive to scientists worldwide.

Table 3. Specialized journals with the terms of 'breast' and 'histochemistry' in their titles in four databases

\begin{tabular}{|c|l|c|c|c|c|}
\hline Rank Journal title & \multicolumn{1}{|c|}{ WoS } & BIOSIS & Scopus & MEDLINE \\
\hline 1. & Breast Cancer Res Treat & 55 & 55 & 19 & 15 \\
\hline 2. & Appl Immunohistochem Mol Morphol & 23 & 22 & 23 & 17 \\
\hline 3. & Breast & 25 & 20 & 12 & 10 \\
\hline 4. & Breast J & 9 & - & 9 & 9 \\
\hline 5. & J Histochem Cytochem & 6 & 6 & 6 & 6 \\
\hline 6. & Breast Cancer Res & 6 & - & 6 & 7 \\
\hline 7. & J Breast Cancer & 6 & - & 7 & - \\
\hline 8. & Breast Cancer & - & - & 9 & - \\
\hline 9. & Breast Diseases & - & - & 7 & - \\
\hline 10. & Clinical Breast Cancer & - & - & 6 & - \\
\hline 11. & Breast Cancer Tokyo & - & - & 5 & 14 \\
\hline 12. & Breast Cancer Basic Clin Res & - & - & 3 & - \\
\hline 13. & Breast Care & - & - & 2 & - \\
\hline 14. & Folia Histochem Cytobiol & - & 2 & - \\
\hline 15. & Acta Histochem Cytochem & - & - & - \\
\hline 16. & Breast Cancer Targets Ther & - & 1 & - \\
\hline
\end{tabular}

The ten most influential scientific institutions from four main countries as detected in WOS and Scopus were comparatively listed in Table 4 . The researchers from the
USA dominated. There was intensive national and international collaboration between the scientists from these and other institutions worldwide. 
Table 4. Most productive institutions on the topic in WoS and in Scopus

\begin{tabular}{|c|c|c|c|c|}
\hline Rank & Institution & Country & WoS & Scopus \\
\hline 1. & University of Texas System & USA & 35 & - \\
\hline 2. & University of Texas MD Anderson Cancer Center & USA & 31 & 14 \\
\hline 3. & Unicancer & France & 31 & 6 \\
\hline 4. & University of British Columbia & Canada & 29 & 11 \\
\hline 5. & University of Pittsburgh & USA & 26 & 7 \\
\hline 6. & Pennsylvania Commonwealth System of Higher Education & USA & 28 & - \\
\hline 7. & University of Nottingham & UK & 20 & 10 \\
\hline 8. & University of Toronto & Canada & 19 & 9 \\
\hline 9. & University of North Carolina Chapel Hill & USA & 19 & 6 \\
\hline 10. & University of California System & USA & 21 & - \\
\hline
\end{tabular}

The bibliometric characteristics of the scientific forums with abstracted publications on the topic in WoS and BIOSIS were demonstrated in Table 5. The scientific forums which had attracted the attention of most participants dur- ing this period are indicated in Table 6. In WoS, 55 different forum titles presented with 132 unique events and contained 587 publications. In BIOSIS, these figures were the following: 42, 112 and 421.

Table 5. Bibliometric characteristics of scientific forums on the topic in WoS and BIOSIS

\begin{tabular}{|l|c|c|}
\hline Parameter & WoS & BIOSIS \\
\hline number of forum titles & 55 & 42 \\
\hline number of unique forums & 132 & 112 \\
\hline number of publications & 587 & 421 \\
\hline number of forums with a single event only & 31 & 30 \\
\hline percentage of these forums & 23.48 & 26.79 \\
\hline maximal number of events of a unique forum & 16 & 15 \\
\hline maximal number of publications in a unique forum & 18 & 18 \\
\hline
\end{tabular}

Table 6. Scientific forums with most events and papers in them on the topic in WoS and BIOSIS

\begin{tabular}{|c|c|c|c|c|}
\hline \multirow[t]{2}{*}{ Scientific forum title } & \multicolumn{2}{|c|}{ WoS } & \multicolumn{2}{|c|}{ BIOSIS } \\
\hline & events & papers & events & papers \\
\hline Annual Meeting of the US and Canadian Academy of Pathology & 16 & 167 & 15 & 147 \\
\hline Annual San Antonio Breast Cancer Symposium & 10 & 79 & 13 & 101 \\
\hline European Congress of Pathology & - & - & 11 & 53 \\
\hline Annual Meeting of the American Association for Cancer Research & 3 & 8 & 13 & 29 \\
\hline Annual Meeting of the American Society of Clinical Oncology & 10 & 20 & - & - \\
\hline European Breast Cancer Conference & 6 & 16 & 7 & 18 \\
\hline Congress of the European Society for Medical Oncology & 5 & 16 & 1 & 6 \\
\hline
\end{tabular}

\section{DISCUSSION}

Our results convincingly proved the dynamic science stratification in this interdisciplinary field. It indicated the necessity of sharing the rich experience, gained by the eminent researchers, with their colleagues from the smaller countries worldwide.

According to an original scientometric concept, there is a unity of the institutionalization, interdisciplinarity and internationalization of contemporary science and university education $[4,5]$. Along with the acknowledged problem-ori- ented denominations of single institutions of different organizational type, the following essential components belong to science institutionalization defined as a historically established disciplinary organization of scientific and higher educational structures [5-7]: i) the organization of national and international scientific forums on a concrete interdisciplinary (or narrow-monodisciplinary) topic; ii) the regular publication of problem-oriented and narrow- or broad-profile inter- or monodisciplinary journals and monographs and their subsequent inclusion in secondary information sources 
and databases; iii) foundation of national and international scientific societies and associations; iv) establishing of corresponding university departments and/or their subdivisions performing a regular students' education; v) introduction of postgraduate studies and preparation of doctoral dissertations; vi) introduction of the topic into university students' curricula, initially, in the form of extracurricular activity such as invited lectures delivered by experts from the same country and abroad, publication of textbooks and manuals, summer schools, etc.; vii) creation and subsequent dynamic development of corresponding paradigms or paradigm circles, etc.

Some newly-published investigations testify to the uninterrupted interest in science institutionalization worldwide.

The styles and spreads of global institutional research are quantified and visualized, as well as the shares of these efforts are measured [8].

Home to many of the oldest research universities and other organizational forms, such as academies and research institutes, Europe is at the heart of scientific productivity between North America and East Asia [9]. The neo-institutional analysis of a comprehensive historical database from 1900 to 2010 uncovers both, stable and dynamic, patterns of production and productivity in the fields of science, technology, engineering, mathematics, and health in Germany, France, Belgium, and Luxembourg and shows the varying contributions of different organizational forms, especially research universities and research institutes. Comparing the institutionalization pathways that create the conditions necessary for continuous and strong growth in scientific productivity identifies the research university as the key organizational form across countries.

Institutionalization framework elements such as nominal, leadership, administrative support, multi-year funding, research targets, formal researcher-to-researcher exchange, visibility, evaluation, and supporting characteristics, are examined in five cases studies of institutionalization framework, in order to explain the development of international university research ventures between US universities, on the one hand, and China and Singapore, on the other hand [10].

The institutionalization of the of Women's Studies Research Centre, Gauhati University in India [11], the institutionalization and professionalization of science policy in Portugal [12] and the stimulation of the institutionalized involvement of society, when accomplishing the policy in the fields of science, technology and innovations in Japan [13], are assessed. The development of the institutionalization of the university education systems in seven countries such as China, Japan, Germany, Qatar, South Korea, Taiwan, and the
USA) during the period between 1945 and 2015 is analyzed, and the expansion of the university education along with growing science dimensions is established [14].

A bibliometric analysis of the top 100 cited manuscripts in robotic surgery shows that 28 papers feature urological surgery, 15 deal with multiple surgical subspecialties, and 13 do with colorectal surgery [15-18]. The USA present the greatest number of publications (68 papers). Johns Hopkins University has published 18 papers.

Another analysis of the top 100 most cited articles among 4651 articles on recurrent glioma in WOS shows that the number of citations varies between 149 and 1471 [19]. Sixty-six articles are published in oncology-specific journals, and 67 are authored by institutions in the USA. Eightytwo papers deal with treatment, six - with genetic mechanisms, seven - with diagnosis, and five - with prognosis [20].

Between 2008 and 2017, a total of 835 hepatocellular carcinoma magnetic resonance imaging publications were identified in WoS Core Collection [21]. The Journal of Magnetic Resonance Imaging has published most articles (79 or $9,46 \%$ ). South Korea has the most publications (199 or $23.83 \%$ ), followed by the USA (190 or $22.75 \%$ ), Japan (162 or $19.40 \%$ ), and China (148 or $17.72 \%$ ).

The institutionalization of neuroethics in Korea is an integral component of the Korea Brain Initiative within neuroscience research [22]. A historical case study of the institutionalization of laboratory work in Japan from the 1880s to the 1930s is performed [23]. A scientometric ranking of top Spanish public universities for 2019 is carried out [24]. The dynamic institutionalization patterns in the field of pediatric Crohn's disease are investigated [25]. The contributions made by Howard Wilcox Haggard for the institutionalization and consolidation of modern alcohol studies in twentieth-century post-Prohibition America are described [26, 27].

\section{CONCLUSION}

Our study demonstrates the capacities of the constellation of scientometric indicators purposefully used for integrated assessment of science institutionalization under the conditions of internationalization in this advancing field. This complex scientometric methodology should become more popular in university curricula, especially within the research methodology courses for postgraduate students and young researchers [6]. It promotes comprehensive problem-oriented analyses and faces the challenges of the timely identification of the essential patterns of scientific advances in hot topics. Our results could be of interest to breast cancer researchers and clinicians from smaller countries, institutional and national science managers and journal editors as well.

\section{REFERENCES:}

1. Kostov I, Ivanov S. [Prevention and prophylaxis in obstetrics and gynecology.] Akush Ginekol. (Sofiia). 2018; 57(2):57-8 [in Bulgarian].

2. Llanos AAM, Lin Y, Chen W, Yao $\mathrm{S}$, Norin J, Chekmareva MA, et al. Im- munohistochemical analysis of adipokine and adipokine receptor expression in the breast tumor microenvironment: associations of lower leptin receptor expression with estrogen receptor-negative status and triple-negative subtype.
Breast Cancer Res. 2020 Feb 11; 22(1):18. [Crossref ].

3. Rüschoff J, Lebeau A, Sinn P, Schildhaus HU, Decker T, Ammann J, et al. Statistical modelling of HER2positivity in breast cancer: Final analy- 
ses from two large, multicentre, noninterventional studies in Germany. Breast. 2020 Feb;49:246-53.

4. Kostov I. [Assessment of the impact of medical standard in obstetrics and gynaecology: organizational, clinical and deontological Aspects] [in Bulgarian]. [Doctoral thesis] Medical University of Varna. 2017. [Internet].

5 . Tomov DT. The unity of interdisciplinarity, institutionalization and internationalization of science: reflections from/on cell biology. Biomed Rev (Varna). 2001;12:41-55.

6. Tomov D, Ivanov K, Kolev N, Donev I. Dynamic institutionalization of research in the field of colorectal tumour markers. J Gastroenterol Compl. 2018;1(2):205.

7. Kirov KG. A scientometric approach to dynamic science institutionalization in the field of laparoscopic proctocolectomy. J Clin Invest Surg. 2019;4(2):88-95.

8. Prathap G. Scale, style and spread of global institutional research. Curr Sci. 2019;116(4):530-5.

9. Powell JJW, Dusdal J. Science production in Germany, France, Belgium, and Luxembourg: Comparing the contributions of research universities and institutes to science, technology, engineering, mathematics, and health. Minerva. 2017;55(4):413-34. [Crossref].

10. Youtie J, Li Y, Rogers J, Shapira P. Institutionalization of international university research ventures. Res Policy. 2017 Nov;46(9):1692-705. [Crossref].

11. Dutta D, Vauquline P. Institutionalisation of Women's Studies Research Centre, Gauhati University: A struggle for space and identity. Space Culture (India). 2018 Jun 28;6(1):16-28.
12. Rollo MF, Brandão T, Queiroz MI. Revising the institutionalization of science policies: Historical contexts and competing models. Portug J Soc Sci. 2018 Mar;17(1):37-61.

13. Kudo M, Yoshizawa G, Kano K. Engaging with policy practitioners to promote institutionalization of public participation in science, technology and innovation policy. JCOM. 2018; 17(4): No 1. [Crossref].

14. Zapp M. Higher education expansion and the growth of science: The institutionalization of higher education systems in seven countries, 19452015. Int Perspect Educ Soc. 2017 Sep;33:37-53.

15. Kostov I, Delchev Y, Yunakova M, Georgiev B, Totsev R. [Possibilities for treatment in stess-incontinence with robotic surgery.] Akush Ginekol. (Sofiia). 2018; 57(2):38-42 [in Bulgarian].

16. Kostov I, Vasilev N, Nacheva A, Lazarov I. [Radical trachelectomy - surgery for preserving woman's fertility in patients with invasive cervical cancer.] Akush Ginekol. (Sofiia). 2013;52(7): 27-30 [in Bulgarian].

17. Connelly TM, Malik Z, Sehgal R, Byrnes G, Coffey JC, Peirce C. The 100 most influential manuscripts in robotic surgery: a bibliometric analysis. J Robot Surg. 2020 Feb;14(1):155-65. [Crossref].

18. Delchev Y, Kostov I, Totsev R. [Tumors in retroperitoneal area. Clinical case.] Akush Ginekol. (Sofiia). 2018; 57(4):33-7 [in Bulgarian].

19. Chen W, Lei C, Liu P, Liu Y, Guo $\mathrm{X}$, Kong Z, et al. Progress and prospects of recurrent glioma: a recent scientometric analysis of the Web of Science in 2019. World Neurosurg. 2020 Feb; 134:e387-99.
20. Nedyalkov K, Magunska N, Bechev B, Kostov I. Survival rate and complications after different type of pelvic exenterations for gynecological cancer. Eur J Gynaecol Oncol. 2019; 40(1):69-73.

21. Yang DW, Wang XP, Wang ZC, Yang ZH, Bian XF. A scientometric analysis on hepatocellular carcinoma magnetic resonance imaging research from 2008 to 2017. Quant Imaging Med Surg. 2019 Mar;9(3):465-76.

22. Jeong SJ, Lee IY, Jun BO, Ryu YJ, Sohn JW, Kim SP, et al. Korea Brain Initiative: Emerging issues and institutionalization of neuroethics. Neuron. 2019 Feb 6;101(3):390-3. [Crossref].

23. Isozaki T. Laboratory work as a teaching method: A historical case study of the institutionalization of laboratory science in Japan. Espacio Tiempo Educ. 2017 Jul-Dec;4(2):101-20.

24. Buela-Casal G, GuillenRiquelme A, Diaz-Roman A, CarneiroBarrera A, Quevedo-Blasco R Research ranking of Spanish public universities (2019). Psicothema. 2019 Nov;31(4): 351-62.

25. Koleva K, Georgieva M. [Dynamic institutionalization of research in the field of Crohn's disease in childhood.] Child Infect Dis, Sofia. 2020; 12(1):3-9 [in Bulgarian].

26. Allred N, Bejarano W, Ward J. Haggard Wilcox Haggard and the Institutionalization of Modern Alcohol Studies. J Stud Alcohol Drugs. 2017 Mar;78(2):325-9. [Crossref]

27. Georgiev S, Savov A, Kostova P, Frandeva B, Kostov I, Zlatkov V. Frequency and characteristic of HPV cervical infection during pregnancy and postpartum and the role of smoking as a predisposing factor. CR Acad Bulg Sci. 2019;72(4):551-8. [Crossref].

Please cite this article as: Yaneva G, Dimitrova T, Ivanov D, Ingilizova G, Slavov S. Institutionalization patterns in breast cancer immunohistochemistry. J of IMAB. 2022 Jan-Mar;28(1):4211-4216.

DOI: https://doi.org/10.5272/jimab.2022281.4211

Received: 07/06/2021; Published online: 28/01/2022

\section{Address for correspondence:}

Sergei Svetoslavov Slavov, MD, PhD

University Hospital of Obstetrics and Gynecology "Maichin dom", Sofia, Department of Obstetrics and Gynecology, Medical University- Sofia, 15, Iv. Ev. Geshov Blvd., 1431 Sofia, Bulgaria e-mail: sergeislavov66@gmail.com 